\title{
Employee referral, social proximity and worker discipline: theory and suggestive evidence from India*
}

\author{
Amrita Dhillon, Vegard Iversen and Gaute Torsvik ${ }^{\dagger}$
}

\begin{abstract}
We propose a new theory to explain why employers mobilize workplace insiders for the hiring of new staff. In settings with incomplete contracts, we show how workplace insiders can help employers tackle recruit discipline challenges at a lower cost. A key idea is that the employer can use sanctions against the referee to keep the new hire in line. Our model predicts that employers will use existing staff of stature and with accumulated goodwill within the firm as referees, since such staff have a personal stake in their choice of recruit. The model also predicts a strong social tie between the referee and the recruit to ensure that the recruit internalizes the costs to the referee of own misbehavior or underperformance. We use a small, in-depth dataset from India to scrutinize how well the predictions of our theory and of the main rival explanations for referral align with hiring patterns, wage and labor turnover observations. We find suggestive support for our theory and argue that these findings are hard to reconcile with rival referral explanations.
\end{abstract}

JEL: J41, J31, D82, D86, O12, O17

Keywords: networks, low- and unskilled jobs, India, moral hazard, employee referrals, efficiency wages, referee incentives, strength of ties.

*This research was funded by the Research Council of Norway. We thank Markus Eberhardt, Parikshit Ghosh, Magnus Hatlebakk, Matt Jackson, Amartya Lahiri, Jeremy Magruder, Francisco Manuel Munoz Martinez, Halvor Mehlum, Stelios Michalopoulos, Abhiroop Mukhopadhyay, Kaivan Munshi, Rohini Somanathan, Chris Woodruff and participants at the ESOP Workshop 'Social networks and urban labour markets in developing countries', the ISI-IGC Conference, the IAS Economics Workshop and the PET development workshop for comments. We are indebted to Sushil Kumar and Jyoti Tripathi for very competent data collection.

†Amrita Dhillon, King's College, London and CAGE Research Affiliate, amrita.dhillon@kcl.ac.uk; Vegard Iversen, Natural Resources Institute (NRI), University of Greenwich, UK: vegard.iversen@gre.ac.uk; Gaute Torsvik, University of Oslo : gaute.torsvik@econ.uio.no 


\section{Introduction}

In developing economies, workers often find jobs through a referral from a person already employed by the recruiting firm. In the World Bank's 2006 MicroEnterprise Survey for India, between $40 \%$ and $65 \%$ of new hires were recruited through the social network of a workplace insider. In Beaman and Magruder's (2012) sample from Kolkata, $45 \%$ of employees had helped a friend or relative find a job with their current employer. While the importance of workplace referrals is widely acknowledged, it is more contested why this recruitment strategy is so widely used.

A large literature has examined the role of social networks for candidates searching for a job and employers looking to hire. During job search, networks may provide valuable information about job openings (Granovetter 1973, 1995; CalvoArmengol and Jackson 2004; Wahba and Zenou 2005; Topa 2011). For employers, disseminating vacancy information through employee networks is easy and inexpensive. Alternately, if employee networks are assortatively matched, firms can mobilise the networks of more able or productive staff to find new recruits with similar traits (Montgomery 1991; Fafchamps and Moradi 2015). Referral-based recruitment may also provide job candidates with more accurate information about a workplace, thereby improving the quality of the recruit-workplace match (Simon and Warner 1992). A downside is that recruiting through referral may involve favoritism, which can be costly for firms (Bramoulle and Goyal 2016).

In this paper we propose an alternative explanation, that workplace referrals can reduce agency costs in employment relations. In our model, an employer uses efficiency wages to align worker and firm interests: we show that the required wage can be lowered if the employer recruits through a workplace insider. To take full advantage of this mechanism, the employer should ask a staff member of stature - who stands to lose if the new recruit underperforms - to act as referee. We show that a strong social tie between the referee and the recruit will be optimal

for the firm. In contrast to the existing literature, we account for referee incentives to act in accordance with the employer's preferred scheme.

The mechanism we explore has been touched upon by Kajisa (2007), and is studied 
by Kugler (2003), Iversen, Sen, Verschoor and Dubey (2009) and Heath (2018). Kugler (2003) and Heath (2018) both assume that referee incentives are satisfied. Our paper adds new theoretical insights by endogenising the referee's incentives and the strength of the tie between the employee referee and the new recruit.

Our referral mechanism appears to be particularly relevant for low and unskilled urban labor markets in developing country settings, where retention and labor management challenges loom large because of strenuous jobs, acute informational constraints and the dominance of informal and incomplete labor contracts. ${ }^{1}$

While it is well known that efficiency wages can reduce absenteeism and labor turnover (Salop 1979), their relevance for handling labor management challenges during modernity transitions has received limited attention (e.g. Kerr, Dunlop, Harbison and Myers 1966). In Pollard's (1963) account of the early industrial revolution, workers unaccustomed to the discipline requirements on the factory floor had highly erratic attendance and $50 \%$ absenteeism on a given day was not unusual. 'Stable' workers were therefore coveted by employers, echoing sentiments among Mumbai employers two centuries later (Holmstrom 1984). For some of the jobs reported on below, about $30 \%$ of the new recruits had left within six months of joining their new workplace. This notable instability resonates with official turnover statistics in India (e.g. Annual Survey of Industries 2011-12) and observations from comparable settings elsewhere (Blattman and Dercon 2018).

We contrast the predictions of our model, first, with hiring patterns in a data set containing in-depth information on how low and unskilled migrants from a deprived area of rural North-India found their first migrant jobs. We observe widespread job entry through a workplace insider and strong referee-recruit social

\footnotetext{
${ }^{1}$ In 2000-01, 86\% of India's manufacturing workers were employed in 17 million small and informal enterprises with the remaining $14 \%$ working for 0.13 million formal enterprises (Kotwal, Ramaswami and Wadhwa 2011). Holmstrom (1984) provides a series of examples of how employers in India use referrals to tackle moral hazard, including from van der Veen $(1979,64-$ 65): 'It is a generally accepted policy among managers to accept labourers on recommendation and as groups. The managers of the above-mentioned factories could tell me how everyone of their workers (from 12 to 35 ) had been introduced. They really prefer to utilize these personal relationships, because it gives them a much stronger grip on their labourers. 'When one man misbehaves, I hold the one who introduced him responsible, and that man will keep the mischiefmaker in check', said one manager.' See also the appeal to kinship morality to galvanise employee effort and attendance among dyeing industry employers in Tamil Nadu (De Neve 2008).
} 
ties. While recruitment is mainly into bottom tier jobs, the typical referee is a firm insider in a high stake job. These seemingly counterintuitive patterns agree with our theory, but are hard to reconcile with rival explanations for referral. ${ }^{2}$

We then provide regression-based assessments of our theory and of the main rival explanations. Using data on worker ability, we first evaluate Montgomery's (1991) influential screening or selection explanation for referral and find no support for this theory or for other rival accounts. We proceed to study the performance of referral wage penalty and job turnover predictions. While caveats about representativity and sample size are necessary, we find suggestive, additional support for our theory, but mainly for recruitment into bottom tier jobs.

The rest of this article is organised as follows. Section 2 presents our main contribution, a new theory of employee referral. Section 3 provides a condensed review of the literature. To assess the relevance of our theory, we first review other empirical evidence supportive of the moral hazard explanation. We then describe the context, introduce our data-set and report descriptive statistics on referral prevalence and the social ties between referees and recruits. To obtain clues about referee stakes, we compare the jobs of workplace intermediaries with the jobs of new recruits. Starting with a table summary of the predictions of our model and of the main rival referral explanations, section 4 first examines whether rival explanations can also account for the strong tie and high stake referee hiring patterns in our data. This is followed by the regression-based empirical assessments. Section 5 concludes.

\section{A theory of employee referral}

Consider a firm that needs to fill a vacancy. No specific skills are required, but worker opportunism is costly for the employer. The firm can hire in the spot market or through employee referral. In the first of two periods, the firm decides

\footnotetext{
${ }^{2}$ Karlan, Mobius, Rosenblat and Szeidl (2009) contend that network based trust should be more important for high-skilled jobs where the employer's profits are more sensitive to worker type; for low-skilled jobs, where type matters less, weak connections are best. Put differently, there should be few referrals in the mainly low and unskilled jobs and labor markets we study here.
} 
whether to recruit through the spot market or employee referral. In each case, the firm offers a contract which can be of two types: (1) an efficiency wage contract with a higher wage but where the worker is fired if caught misbehaving or (2) a contract paying the worker's reservation wage (normalized to 0 ).

Labour supply for such unskilled jobs is infinite, so that the odds of a worker finding a job paying efficiency wages through anonymous search are zero: the probability of an employer finding a worker in the spot market is 1 . The worker can always find employment at the 0 reservation wage. ${ }^{3}$ Conditional on recruiting through referral, the employer can make (request) referral specific transfers to (from) the referee who gets the opportunity to recruit from his network.

In the second period workers choose behaviour, the employer checks performance and pays the corresponding wages.

\subsection{Efficiency wages with and without referrals}

The new worker produces a profit $e-w$ if he behaves well and $1-w$ if he misbehaves, where $e>1$ and $w$ is the worker's wage. The costs to the firm of worker misconduct are $c=(e-1)$. The worker gains $\alpha c$ if he behaves opportunistically, with $\alpha<1 .^{4}$ The firm monitors employees and detects misconduct with a given probability $q \in(0,1)$. A worker caught misbehaving loses his job and gets a reservation utility equal to 0 .

\section{Efficiency wage in the spot market}

If the worker behaves well, his payoff is the (efficiency) wage $w_{s}$ while his expected payoff if misbehaving is $(1-q) w_{s}+\alpha c$. The spot market efficiency wage is the minimum wage that ensures worker compliance:

$$
w_{s}=\frac{\alpha c}{q}
$$

\footnotetext{
${ }^{3}$ Hence, the bargaining power lies with employers; our results are not sensitive to this distribution of bargaining power.

${ }^{4}$ This is equivalent to assuming that the cost of effort is $\alpha c$.
} 
The efficiency wage is increasing in the opportunity cost of behaving well, and decreasing in the probability of being detected when misbehaving.

\section{Efficiency wages with employee referrals}

A key feature of employee referral is that the firm can sanction both the referee and the new recruit if the latter misbehaves. That is, the referee becomes an insurance against recruit misbehaviour since he will suffer a loss in income, promotion prospects and workplace stature if his recommended worker misbehaves. The recruit's sensitivity to this loss increases with the strength of the social tie to the referee. To formalize, let $\rho$ measure the social proximity between referee and recruit; a higher $\rho$ indicates a stronger social tie (closer kinship or friendship). Let $R$ denote the potential loss to the referee if the new worker misbehaves. ${ }^{5} \mathrm{~A}$ well-behaved referred worker is paid the wage $w_{r}$, while the expected wage if misbehaving is $(1-q) w_{r}+\alpha c+q(-\rho R)$. The referral efficiency wage, the minimum wage that ensures worker compliance, is given by

$$
w_{r}(\rho)=w_{s}-\rho R
$$

Equation (2) shows that the employer can offer a lower wage to prevent misconduct when hiring through employee referral. ${ }^{6}$ This is similar to Kugler (2003), but the mechanism is different. In Kugler (2003), peer pressure makes it costly for the new recruit to exert less effort than the referee: by selecting a referee exerting peer pressure through own high effort, the employer can ensure higher recruit effort at a lower cost. In contrast, in our set-up, the strength of the social tie between the referee and the new recruit determines the social pressure. This social pressure intensifies further with referee stakes, captured by $R$ : the higher these stakes, the lower the referral efficiency wage.

In Heath (2018), as in our model, referees understand that they can be punished

\footnotetext{
${ }^{5}$ While we are agnostic about their origins, another possible source of referee rents is the same as for the potential recruit: efficiency wages to prevent opportunistic behavior.

${ }^{6} \mathrm{~A}$ lower wage implies that there are instances when referrals enhance efficiency. Since $\alpha<1$ it is always efficient for the worker to exert effort, but the employer will only choose to induce worker effort if $w_{s} \leq c$. Hence, referral based hiring enhances efficiency if $w_{s}>q>w_{r}(\rho)$.
} 
if their recommended worker misbehaves. However, in her model there is no role for referee incentives or for the strength of ties. Neither Kugler (2003) nor Heath (2018) consider referee incentives explicitly, which we analyze next.

\section{$2.2 \quad$ Referee incentives}

Absent any referee incentive problems, the employer wants the strongest possible tie between referee and recruit to minimize the referral efficiency wage. It is not, however, obvious that referee and employer interests about the preferred strength of this tie are aligned. If not, we need to examine how the employer can induce strong tie referrals and whether this is profitable.

We consider two types of referral related transfers that affect referee utility. The referee may receive transfers from the recommended worker and his family and network. We denote these transfers $B(\rho)=v(\rho)+b(\rho)$ where $v$ captures the social utility accruing to a referee from helping someone in his network find a job. Social status, approval and reciprocal aid are captured by this term. Helping someone into a job may also provide the referee with intrinsic utility ("warm glow" altruism - see Andreoni (1990)). With these interpretations, it is reasonable to assume that $v(\rho)$ is increasing in $\rho$. The second term, $b$, captures monetary transfers (bribes) the worker may pay the referee. ${ }^{7}$ It is reasonable to assume that the referee can claim a fraction of the wage premium a referred worker receives in his new job. ${ }^{8}$ For the rest of the paper, we assume that $b(\rho)=\gamma^{\rho} w_{r}(\rho)$, with $\gamma^{\rho}<1$.

In addition, the employer may also make referral related transfers. Let $T(\rho)$ be the monetary equivalent of the transfer the employer offers (demands from) the referee if the recommended worker is hired.

\footnotetext{
${ }^{7}$ Since the game is modelled as one shot, we have not distinguished between one time payments and the present value of future payments. Indeed, it would make sense for the worker to pay the referee a one time bribe to get the job. On the other hand, the wage and the nonmonetary benefits are a per period payment to the worker while the referee receives a one shot payment from the firm $T(\rho)$ to induce him to bring the right (strong social tie) worker to the firm. We can therefore interpret the one shot payoffs as the equivalent annualised value of the lump sum payments.

${ }^{8}$ In an adverse selection model of referral, Karlan et al (2009) assume, similarly, that a recruit can bribe the referee to portray him as high-skilled. The bribe is a fraction of the wage premium high-skilled workers earn.
} 
The referee's utility (the part affected by the referral decision) is given by $U(\rho)=$ $R+B(\rho)+T(\rho)$ and the referral related profit for the employer is given by $\Pi(\rho)=e-w_{r}(\rho)-T(\rho)$. In the analysis below, we assume only two strengths of the social ties, $\rho=\left(\rho^{H}, \rho^{L}\right)$, with $\rho^{H}>\rho^{L}$. Our results extend to cases with more fine grained social connections.

\subsection{Complete information}

Solving for the sub-game perfect equilibrium of this two stage game, notice that in the last period $\rho$ has already been chosen, so $w_{r}(\rho)$ is the minimum efficiency wage for a given $\rho$. In the first stage, the employer chooses $\rho$ to maximize $\Pi(\rho)$. For a fixed $\rho$, maximizing profits implies paying the referee the minimum to induce his participation: Let $U(0)=R$ denote the referee's utility if he declines to refer a worker. Participation requires $U(\rho)=U(0) \Rightarrow T(\rho)=-B(\rho)$ and the employer

chooses $\rho$ to maximize $\Pi(\rho)=e-w_{r}(\rho)+B(\rho)$. Thus, we have $\Pi\left(\rho^{H}\right)-\Pi\left(\rho^{L}\right)=$ $\left[w_{r}\left(\rho^{L}\right)-w_{r}\left(\rho^{H}\right)\right]+\left[B\left(\rho^{H}\right)-B\left(\rho^{L}\right)\right]$.

We know from (2) that the first bracket term is positive. The second term can be negative or positive depending on whether social utility or the 'bribe' from the recruit dominates. If $B\left(\rho^{H}\right)>B\left(\rho^{L}\right)$, the employer prefers strong ties since this will reduce wage costs for both recruit and referee. If, however, $B\left(\rho^{H}\right)<B\left(\rho^{L}\right)$, the employer may want the referee to choose a worker he is weakly tied to. When could this happen? Recall that we assumed $b(\rho)=\gamma^{\rho} w_{r}(\rho)$, with $\gamma^{\rho}<1$. If the fraction of wages the referee receives is independent of the strength of the social tie, the employer always prefers a strong tie referee-recruit relationship. But if $\gamma^{H}$ is sufficiently lower than $\gamma^{L}$, the employer will prefer a weak social tie since this facilitates extracting the larger "bribe" the referee is paid by the recruit. A weak tie is preferred if $w_{r}\left(\rho^{L}\right)-w_{r}\left(\rho^{H}\right) \leq B\left(\rho^{L}\right)-B\left(\rho^{H}\right)$, i.e. if:

$$
\frac{w_{s}\left(\gamma^{L}-\gamma^{H}\right)-\left(v\left(\rho^{H}\right)-v\left(\rho^{L}\right)\right)}{\rho^{H}\left(1-\gamma^{H}\right)-\rho^{L}\left(1-\gamma^{L}\right)}>R .
$$

The employer prefers a weak tie referee-recruit relationship if referee stakes are sufficiently low. 
Recall that with the spot market efficiency wage contract, employer profits are $\Pi(0)=e-w_{s}$. Hence, $\Pi(\rho)-\Pi(0)=\rho R-T(\rho)=\rho R+B(\rho)>0$, regardless of the strength of ties chosen in equilibrium. To summarize, employers always prefer referrals to the spot market, conditional on the use of efficiency wage contracts. However, the choice of strong or weak ties depends on whether referee utility is increasing or decreasing in $\rho$. If referee utility is increasing in $\rho$, strong ties are preferred while if referee utility is decreasing in $\rho$, strong ties are preferred only if $R$ is sufficiently large.

\subsubsection{Collusion between referee and recruit}

Employers are unlikely to have complete information about a candidate referee's social network. It might be common knowledge that everyone has a weak tie person they can recommend, but not everyone has a suitable person they are strongly tied to: everyone has a $\rho^{L}$ in their network, but whether there is a $\rho^{H}$ is only known by the referee.

Assume first that the employer can verify the true social tie once the worker is introduced. This takes us back to the complete information case since the contract the employer offers the referee can be made contingent on the strength of the tie.

Whichever social tie the employer prefers, he offers the referee a contract $\Theta=$ $\left\{T\left(\rho^{L}\right)=-B\left(\rho^{L}\right), T\left(\rho^{H}\right)=-B\left(\rho^{H}\right)\right\}$ that guarantees the referee his reservation utility $R$ whether he recommends a recruit he is strongly or weakly tied to. With this contract, he is willing to bring the tie the employer prefers.

A more interesting situation arises if the employer is unable to verify the true social tie. With asymmetric information, the employer may have to provide the referee with incentives to disclose the true social tie. To illustrate, assume that $B\left(\rho^{H}\right) \geq B\left(\rho^{L}\right)$ and the employer prefers strong ties with complete information. When the employer cannot verify the social tie, a referee offered the above contract will recommend a $\rho^{H}$ person but misrepresent the tie as $\rho^{L}$.

To characterize the optimal contract, let $U(\rho, \hat{\rho})$ represent referee utility if he refers a worker with social tie $\rho$ but presents the tie as $\hat{\rho}$. We have $U\left(\rho^{H}, \rho^{L}\right)=$ $v\left(\rho^{H}\right)+b\left(\rho^{H}\right)+T\left(\rho^{L}\right)$ and $U\left(\rho^{H}, \rho^{H}\right)=v\left(\rho^{H}\right)+b\left(\rho^{H}\right)+T\left(\rho^{H}\right)$. To induce truth- 
ful reporting $U\left(\rho^{H}, \rho^{H}\right) \geq U\left(\rho^{H}, \rho^{L}\right)$, hence the employer must choose $T\left(\rho^{H}\right) \geq$ $T\left(\rho^{L}\right)$. Exploiting the fact that the participation constraint requires $T\left(\rho^{L}\right)=$ $-\left(v\left(\rho^{L}\right)+b\left(\rho^{L}\right)\right)$, implies $T\left(\rho^{H}\right) \geq-\left(v\left(\rho^{L}\right)+b\left(\rho^{L}\right)\right)$. This (incentive) constraint binds iff $B\left(\rho^{H}\right) \geq B\left(\rho^{L}\right)$.

The cost minimizing contract disclosing the strong social tie is given by $\tilde{\Theta}=$ $\left\{T\left(\rho^{L}\right)=-B\left(\rho^{L}\right), T\left(\rho^{H}\right)=-B\left(\rho^{L}\right)\right\}$. It is easy to check that this contract does not give a referee with a weak tie to the recruit an incentive to misrepresent the tie (even if he could). Given $B\left(\rho^{H}\right) \geq B\left(\rho^{L}\right)$ and $w_{r}\left(\rho^{H}\right)<w_{r}\left(\rho^{L}\right)$, the employer will offer a contract that induces a referee with a strong social tie to reveal the true tie.

With a separating contract $\tilde{\Theta}$, we have $\Pi\left(\rho^{H}\right)-\Pi\left(\rho^{L}\right)=w_{r}\left(\rho^{L}\right)-w_{r}\left(\rho^{H}\right)>0$. In the complete information case, this difference is given by $\left[w_{r}\left(\rho^{L}\right)-w_{r}\left(\rho^{H}\right)\right]+$ $\left[B\left(\rho^{H}\right)-B\left(\rho^{L}\right)\right]>0$ which exceeds the incomplete information case, since the employer needs to leave a "referral" rent equal to the difference $B\left(\rho^{H}\right)-B\left(\rho^{L}\right)$ to the referee (a rent above $R$ ) to induce him to reveal that the worker is $\rho^{H}$.

Suppose instead that $B\left(\rho^{L}\right)>B\left(\rho^{H}\right)$ and $R$ is sufficiently small. With complete information, the employer prefers a weak tie referral since he can extract the entire surplus accruing to the referee. This is not possible when information is incomplete, since $T\left(\rho^{H}\right)=T\left(\rho^{L}\right)=-B\left(\rho^{H}\right)$. Hence, with incomplete information and $B\left(\rho^{L}\right)>B\left(\rho^{H}\right)$, the employer will prefer strong ties.

Another way to state this result is that collusion between referee and recruit can reduce the employer's ability to extract rents: a direct implication is that employers always prefer strong ties in the presence of collusion. Moreover, as before, the minimum gain from referrals relative to the spot market is $\Pi(\rho)-$ $\Pi(0)=\rho R>0$ so that conditional on efficiency wage contracts being used, employers always prefer referrals.

\subsubsection{Referee risk}

We started off asking why referees should agree to refer given the risk of losing rents or employer goodwill. Informal conversations with individuals who agreed and declined offers to recruit for their firm show that this is a real concern. This 
risk is not captured in our model, since on the equilibrium path the worker never misbehaves. This section introduces the possibility of mistakes or accidents even if the recruit never misbehaves, so that the referee, more realistically, is exposed to risk when recommending a worker.

Suppose that the inspection technology is faulty and there is a chance $\epsilon$, conditional on inspection, that the worker is charged even if he didn't misbehave. The spot market payoff for a well-behaved worker now becomes $((1-q)+q(1-\epsilon)) w_{s}$. If misbehaving, he gets $w_{s}(1-q)+\alpha c$. The spot market efficiency wage is given by:

$$
w_{s}=\frac{\alpha c}{(1-\epsilon) q}
$$

Referral efficiency wages must now satisfy $w_{r}((1-q)+q(1-\epsilon)) \geq w_{r}(1-q)+$ $\alpha c+(1-q) \rho R$, which gives a referral efficiency wage:

$$
w(\rho)=w_{S}-\rho R
$$

as before.

The referee's participation constraint will change since he must be compensated for the risk incurred when agreeing to be a referee. Participation requires $U(\rho)(1-$ $q+q(1-\epsilon)) \geq U(0)$, i.e. $U(\rho) \geq \frac{U(0)}{1-\epsilon}>U(0)$. Thus, the firm must pay $T(\rho)=$ $\frac{U(0)}{1-\epsilon q}-U(0)-B(\rho)$ to ensure referee participation. Substituting for $U(0)=R$, the transfer that guarantees participation is given by $T(\rho)=\frac{\epsilon q R}{1-\epsilon q}-B(\rho)$. Let $\rho^{*} \in\left\{\rho^{L}, \rho^{H}\right\}$ denote the employer's optimal choice of $\rho$. Assuming complete information (results easily extend to incomplete information), referral is now preferred by the employer if $\Pi(\rho)-\Pi(0)=\left(e-w_{r}\left(\rho^{*}\right)-T\left(\rho^{*}\right)\right)-\left(e-w_{S}\right) \geqslant 0$. Hence, using the expression for $T\left(\rho^{*}\right)$ derived from the participation constraint, a sufficient condition for preferring referral, conditional on the use of efficiency wage contracts, is that

$$
\rho^{*} \geq \frac{\epsilon q}{(1-\epsilon q)(1-\gamma)} \equiv \widehat{\rho}
$$

Referee rewards for referral increase by $\frac{\epsilon q R}{1-\epsilon q}$ compared to the no-risk benchmark. Note that the relationship between the referral efficiency wage and the spot market efficiency wage is unaffected. Hence the employer's choice between a strong or 
weak tie referral is not affected by the type of risk examined here.

We conclude that when referral exposes a referee to a positive risk of losing workplace rents, referrals remain cheaper than the spot market as long as the social tie is sufficiently strong, i.e. when the feasible $\rho>\hat{\rho}$.

\subsection{Non-efficiency wage contracts}

So far we have established that conditional on efficiency wages, referrals are preferable to anonymous hiring. It is straightforward to show that when the costs of opportunism to employers are sufficiently low, employers prefer paying workers their reservation wage. If employers pay reservation wages, $\Pi_{S}=1$ : with efficiency wages and referral, profits are $\Pi(\rho)=e-w_{r}\left(\rho^{*}\right)-T\left(\rho^{*}\right)$. Thus efficiency wages are preferred when $\Pi(\rho) \geq 1$. With no mistakes in detecting misbehaviour , $\Pi(\rho)-\Pi_{S}=c-\frac{\alpha c}{q}+\rho^{*} R+B\left(\rho^{*}\right)$. This expression is positive if $\frac{\alpha}{q}<1$, i.e. as long as the detection probability exceeds $\alpha$. With a positive probability of mistakes,

we get $\frac{\alpha}{(1-\epsilon) q}<1$. In general, when the worker's opportunity cost of misbehaving is given by $w_{S}$, efficiency wages are optimal whenever $c \geq w_{S}-\rho^{*} R-B\left(\rho^{*}\right) \equiv \bar{c}$. It is evident that $\bar{c}$ is decreasing in $R$. Moreover, if the referee's utility is increasing in $\rho, \bar{c}$ is decreasing in $\rho$ as well.

Summing up, our theory requires that the referee and the new recruit are in the same workplace. To align referee and employer incentives, the referee should have high stakes and stand to lose if the new recruit underperforms. We expect a strong social tie between the referee and the recruit.

For the recruit wage, a referral wage premium or penalty are both possible. From above, it follows that employers will pay efficiency wages in jobs where the costs of opportunism exceed a threshold: below this threshold, paying efficiency wages will not be worthwhile. For jobs below the threshold, our theory predicts a referral wage premium: the worker will either be hired through referral and offered an efficiency wage contract or hired anonymously and paid the reservation wage. Notice that firms will pay efficiency wages - also in the spot market - for jobs where the costs of opportunism are sufficiently high: in such jobs our theory predicts a referral wage penalty. 


\section{$3 \quad$ Empirical evidence}

Our theory delivers distinct empirical predictions. To assess the theory's relevance, we first review other evidence supportive of the moral hazard explanation. We then introduce the context, our primary data-set and descriptive statistics focusing on 'the same workplace', 'strong social tie' and 'high stake referee' predictions. We carefully assess whether our theory is consistent with these descriptives.

\subsection{Other evidence supportive of the moral hazard expla- nation}

Montgomery's (1991) selection or screening model provides an influential explanation for hiring via referral and prior evidence on the relevance of the moral hazard explanation is scant. Using a population wide and employer-employee matched data-set from Sweden, Kramarz and Skans (2014) (KS from now) find strong social ties to be a key determinant of where young workers get their first job. Social ties are more important when the recruit's position is weak (low education, long unemployment spells) and social tie effects more pronounced for a parent with high status in the firm which is captured by a higher wage or longer tenure. Soon after the child is hired, the parent experiences a wage reduction while the referred child's wage is lower than the wage of similar level entrants.

Although KS cite Montgomery (1991) to pinpoint the mechanism of interest, their findings are at odds with a pure selection story. As KS recognise, two key observations - that new recruits have lower observable skills and that both the employee referee and the recruit experience a wage penalty - are inconsistent with Montgomery's (1991) prediction of a wage premium for both the referee and the recruit. The KS findings are, however, partly consistent with our model which, in this example, would predict referee and recruit wage penalties. ${ }^{9}$

\footnotetext{
${ }^{9}$ This reflects an element of joint liability in our model where the referee accepts the full risk and may be sanctioned by the employer - through a wage penalty - if the recruit underperforms. In the KS example, the recruit wage penalty reflects the recruit's lower skills. A distinguishing feature of our theory is that it predicts a recruit wage penalty also for a recruit with the same ability and qualifications as other new hires.
} 
Heath (2018) reports a moral hazard channel in referrals in Bangladeshi garment factories. She postulates that high ability employees will be induced to accept contracts that offer implicit joint liability with the new recruit. Captured by positively correlated referee and recruit wages, she finds that the referee is punished when the recruit underperforms. Her model also predicts more variance in referee wages which is supported by her data. In Heath's (2018) theory, however, referee incentives are not modelled. She reports evidence of strong ties between referees and recruits, which is what our (but not her) model predicts in order to satisfy the referee's participation constraint.

Antoninis (2006) argues that social networks such as family and close friends are particularly useful for recruitment into low skilled jobs, where ability is claimed to matter less. Using data from an Egyptian manufacturing firm, he finds that new recruits referred by an employee with direct experience of their productivity are paid higher starting wages: when referred by friends and relatives (as in our moral hazard explanation), a wage penalty is more likely. ${ }^{10}$ He also emphasizes the distinction in referrals between high-skill and low-skill jobs where - as in our study - both the type of vacancy and the type of network called upon is relevant for distinguishing situations where wage premia and wage penalties are expected. Further and when the social tie between the referee and the recruit is strong (e.g. family as opposed to co-workers), referrals are likely to be in low skilled jobs where recruits are likely to experience wage penalties. Antoninis (2006) does not provide an explanation for these results which, we argue, will be consistent with our moral hazard explanation as long as referred and non-referred workers have similar ability and other productive traits.

\footnotetext{
${ }^{10}$ This could simply reflect favoritism and that these new recruits are less productive than others. Such referrals are costly for the firm. Pistaferri (1999) similarly documents a wage penalty for workers recommended by family and friends but is unable to control for worker ability. These facts are consistent with our explanation but since the two studies lack information about worker ability or productivity, it is not possible to distinguish between our moral hazard and a favoritism explanation for referral.
} 


\subsection{Referrals for migrant workers: data and descriptive statistics}

\subsubsection{Data and context}

Our data-set is from two villages in Bijnor district in western Uttar Pradesh (UP), an impoverished rural setting with an interesting social and religious blend. ${ }^{11}$ At $41 \%$, Bijnor district has the third highest percentage of Muslims in the population in UP. The largest Muslim group in our study villages are the Ansaris (Julahas), traditionally a weaving community. Jats, the main local landowners, and Chamars, who are Scheduled Castes and traditional leatherworkers, are the most conspicuous Hindu communities.

We surveyed a random sample of households in Kasba Kotra and Jagannathpur villages in Nagina tehsil and conducted separate interviews with household members with a labour migration history. ${ }^{12}$ Among the 316 individuals with a labour migration history, only two were women. Through repeated village visits and tracing in e.g. Chandigarh, Delhi, Mumbai, Pune, nearby Haridwar and known local factory clusters, we were able to interview 287 or $90.8 \%$ of these migrants. The first interviews were conducted in May 2009, the last in February 2010.

Each migrant was interviewed in depth, with special emphasis on the process of entering the first migrant job. To illustrate, we asked whether the first migrant job was pre-arranged, whether the migrant received a job offer and if the person who made the offer was working for the migrant's first destination employer. If the person was working for the destination employer, we defined these as workplace referrals, of which employee referral forms a subset. ${ }^{13}$ For the person making the

\footnotetext{
${ }^{11}$ UP has the highest prevalence of stunting $(47 \%)$ among children $(<3$ years $)$ in India and well documented quality shortfalls in public services, including government schools (e.g. Dreze and Gazdar 1998).

${ }^{12} \mathrm{An}$ individual is understood to have a labour migration history if he has spent a minimum of one month continuously living away from the village for employment purposes. Following Winters et al (2001), we define a household as (i) people living under the same roof and who eat from the same kitchen and (ii) offspring or other family members who would otherwise reside with the unit in (i) but who have migrated for work.

${ }^{13}$ The term workplace referral captures that a workplace referee may be an employee of the firm or the firm owner. Notice that owners have particularly strong incentives to recruit well on the firm's behalf.
} 
job offer on behalf of a firm, information was collected from the migrant on the relationship to the migrant and on the referee's job (job title) within the recruiting firm. ${ }^{14}$

Similar information was collected for what we call main contacts, described below. In-depth information was also collected on e.g. migrant education, work experience, career path and skills along with proxies for individual unobservables expected to matter in these employment relations, including a Raven-type ability test which is discussed in detail below.

\subsection{Descriptive statistics}

Table 1 presents information on the first migrant jobs and sector of work by social group. The concentration of Ansaris - traditionally a weaving community in bakery jobs is noteable.

\section{[ INSERT TABLE 1 ABOUT HERE]}

Figure 1 panel a) shows that first migrations are spread out in time, with the main bulk occurring during the last decade. Compared to other studies (e.g. Lucas 1997), the age at first migration is low. Panel b) shows the high proportion of first migrants in the 15-20 age range and the significant numbers also below that.

[INSERT FIGURE 1 panel a) and FIGURE 1 panel b) ABOUT HERE]

The youngest migrants are concentrated in the Ansari-dominated bakery sector which absorbed about two-thirds of this group.

\footnotetext{
${ }^{14}$ In this retrospective migrant sample, the timing of the first labour migration stretches from 1950 till 2009. Given this spread, recall poses a methodological hazard. Testing recall among migrants, Smith and Thomas (2003) found that subjects recall salient moves more accurately: the first migrations analysed here are typically salient.
} 


\subsection{The role of social networks in getting the first migrant job}

Table 2 reports the mode of entering the first migrant job and distinguishes between migrants with and without pre-arranged jobs. The latter left for destination without a job waiting, the former had a job lined up. For each category, we distinguish workplace referrals, where a person intermediates and makes a job offer on behalf of his employer, from indirect network-based entry where a main contact, usually the person making a job offer, works elsewhere. ${ }^{15}$

\section{[INSERT TABLE 2 ABOUT HERE]}

For those with pre-arranged jobs, the 'other' category includes recruitment through labour contractors (9.8\% of total) and formal labour market entry, e.g. job offers after responding to private sector and government job advertisements $(2.8 \%$ of total). For those without prearranged jobs, the residual category (6.3\% of total) comprises 'orthodox' destination job search and directly approaching a destination spot market for skilled or unskilled labor.

Workplace referral is observed for $61.3 \%$ of these first migrant jobs. ${ }^{16}$ This estimate tallies with the 2006 World Bank Microenterprise survey for India, the first 'large' sample of small enterprises to record employee referral across sectors of a developing economy. Using WB data, Table A1 (Online Appendix) shows a high average incidence (above 50\%): in garments and textiles more than $60 \%$ of new hires were recruited through employee referral.

We next consider the main predictions of our theory and start with the strength of the tie between referee and recruit. Table 3 shows that kin accounted for $78.4 \%$ of the referral observations with a member of the same household acting as intermediary in $29 \%$ of these observations. Village friends and acquaintances

\footnotetext{
${ }^{15}$ Apart from the 'indirect' category there are a few instances where a migrant relies on the assistance of a main contact (e.g. a more experienced migrant) for finding short term jobs in a destination labour 'chowk' (spot market) or for setting up a business. For all referees and main contacts, we collected information on relation to the migrant and job title.

${ }^{16}$ This is slightly below Munshi and Rosenzweig's (2006) estimate of 'referral' in male blue collar jobs in Mumbai: notice that our definition of workplace referral is more narrow and precise.
} 
add up to $15.9 \%$. The most important relations are 'other' relatives. ${ }^{17}$ Our descriptives thus suggest that strong, kinship-based social ties dominate weak ties in referral-based entry into first migrant jobs.

\section{[INSERT TABLE 3 ABOUT HERE]}

As noted, the second main prediction of our theory is that employers will use employees with high stakes in the firm as referees. A plausible proxy for such stakes is the status of the referee's job. To examine the role of high stake referees, we first rank jobs according to their status. The rich diversity of the jobs of referees, main contacts and new migrants in our data-set is illustrated by the nine job categories in Table A2 (Online Appendix).

Our initial ranking is informed by the Indian National Classification of Occupations (NCO 2004) which was derived from the ISCO occupational classification of the ILO and officially modified to fit the Indian context. ${ }^{18}$ From these initial nine, we simplify and compress the job categories down to three: enterprise owners and skilled occupations are represented by category $1 ;{ }^{19}$ apprentice jobs with skill acquisition in progress and semi-skilled jobs are category 2. The distinguishing characteristic of the bottom-tier, category 3 jobs is that these jobs combine the NCO elementary occupation classification with with low status hard manual labour, cleaning of utensils, equipment and other menial tasks.

Using these categories, consider our theory's prediction that workplace referees are in high stake, prestigious jobs. For the 176 migrants recruited through workplace referral - as Figure 2 panel a) shows - 85.8\% of the workplace referees are in category 1 jobs while only $3.4 \%$ of referees are in bottom-tier, category 3 jobs.

\footnotetext{
${ }^{17}$ If interpreted too liberally, 'relative' might blur the distinction between strong and weak ties. The largest categories of 'other relative' in table 3 are cousins (32), uncles (30) and brotherin-laws (17).

${ }^{18}$ In Table A2, category 1 comprises enterprise owners: bakery entrepreneurs is the largest such group. Categories 2 to 9 are ranked according to the skill requirements of jobs. Category 2 covers high skill and high prestige jobs, 3 are jobs with comparatively high skill intensity and category 4 skilled, but less skill-intensive. Category 5 are vendors, who are self-employed, respected and often have useful connections. Category 6 are apprentice jobs that cover a spectrum of practical and technical skills in the process of being acquired. Category 7 represents semi-skilled jobs while categories 8 and 9 are physically demanding and unskilled manual jobs.

${ }^{19}$ Notice that this aggregration of skilled workers/referees into the single and heterogenous category 1 does not affect the main results.
} 
A large majority of referees are thus in higher status, more skilled and higher stake jobs. How does this occupational profile of referees compare with the status and skill-profile of the jobs that migrants are recruited into? The contrast is compelling: about $78 \%$ of the first migrant jobs are in categories $2(36.4 \%)$ and 3 (42.0\%), where the latter - as noted - make up the bottom tier.

[INSERT FIGURE 2 panel a) and FIGURE 2 panel b) ABOUT HERE]

Figure 2 demonstrates that links to the owner or to employees in skilled and more prestigious jobs within the hiring firm are crucial, even for acquiring predominantly low tier first migrant jobs. ${ }^{20}$

Summing up, these descriptives suggest a close correspondence between our theory's 'same workplace', 'strong tie' and 'high stake workplace referee' predictions and our data. We next consider whether plausible rival explanations for referral can also account for these notable (and counterintuitive) hiring patterns. This is followed by the regression-based assessments of our theory and of the same rival explanations.

\section{Empirical analysis}

\subsection{Assessing the merit of rival explanations}

Table 4 summarises the predictions of our theory $(\mathrm{MH})$ and of the five rival explanations considered here. In addition to the information mechanism (i) and the Montgomery (1991) selection or screening mechanism (ii), we consider the sociality mechanism (iii), which we have not seen discussed in the literature. ${ }^{21}$ If individuals enjoy working with relatives and friends, an employer can extract the resulting rent and earn more profit by hiring through workplace referrals. The improved matching explanation (Simon and Warner 1992) is the fourth (iv) and

\footnotetext{
${ }^{20}$ Do owners and employee referees differ in their recruitment behaviour? Our descriptives suggest considerable overlap: in about one third of cases where owners recruit, they chose a household member (compare with table 3 ). In $43 \%$ of the same instances, the owner recruited another relative. The theory suggets that an employer who chooses a relative or close friend is motivated by ensuring low opportunism via social preferences.

${ }^{21}$ We are grateful to a reviewer for this suggestion.
} 
favoritism or nepotism (e.g. Bramoulle and Goyal 2016) the fifth (v) and final mechanism. As above, the status of the referee's job is our proxy for stakes in recruit performance while turnover is our moral hazard proxy. We first examine the consistency between predictions and descriptives (Table 4, panel A), before empirically assessing the performance of ability, wage penalty and labor turnover predictions (Table 4, panel B).

[INSERT TABLE 4 ABOUT HERE]

\subsubsection{The social tie and high stake referee predictions}

Starting with the information explanation (Table 4, panel A, column 2), existing employees are likely to acquire early and privileged information about a job vacancy. This information advantage could explain why job entry through workplace insiders is so prevalent. While such 'information dissemination' roles of networks are often alluded to (e.g. Wahba and Zenou 2005), this is hard to reconcile with our strong tie job entry observations since weak tie job search and information dissemination would be more efficient (Granovetter 1973). If information dissemination was the main driver of referral in our sample, we would expect migrants to find jobs through low-skilled, entry level workers (rather than high stake referees) since entry level workers (a) are likely to be more numerous than other staff in the average sample enterprise and (b) are the type of contacts a low-skilled, representative job seeker is particularly likely to know.

For the main screening or selection explanation for referral (column 3), Montgomery (1991) assumes homophily or assortative matching in employee networks: by recruiting through the networks of talented (or more productive) staff, employers can mitigate informational asymmetries about ability or other valuable, hard to observe candidate traits. If correct, we would expect similar referee-recruit jobs and weak referee-recruit ties: both contrast starkly with our descriptives.

We next consider the sociality explanation (column 4). While consistent with our strong tie observations, it seems reasonable to expect the referee and the recruit to be in similar jobs: this is, again, different from what we observe. For the matching explanation (column 5), neither a strong tie nor high referee stakes are 
required. Finally, the favoritism explanation (column 6) is plausibly consistent with our strong tie and high stake referee observations.

Summing up, while the high stake and strong social tie patterns in our data are consistent with our theory, partly consistent with the sociality explanation and consistent with the favoritism explanation, they are hard to reconcile with the other rival explanations. To progress, we empirically assess the ability, wage penalty and turnover predictions of our theory and of the same rival explanations.

\subsubsection{Referral and (unobserved) recruit ability}

Table 4, panel B, outlines the worker ability predictions. To be advantageous for the recruiting firm, the unobserved ability of workers recruited through our referral mechanism should be at least on par with other recruits (column 1). Given the influence of Montgomery (1991), we examine whether individuals recruited through referral have superior unobservable traits.

At the end of each migrant interview, we implemented a simplified Raven-type innate ability test. One advantage of such a test is its claimed neutrality to culture and to a person's educational and other exposure (e.g. Boissiere, Knight and Sabot 1985). Raven-type progressive matrices tests have, accordingly, been widely used in developing country settings, including in Mani, Mullainathan, Shafir and Zhao's (2013) poverty and cognitive performance research. Our abridged six matrices test was implemented in a careful, standardised manner that closely resembled Mani et al.'s (2013) approach (see Online Appendix Figure A1).

In Table 5 below, the binary dependent variable takes the value 1 if individual i was recruited through workplace referral and 0 otherwise. If referral is a screening device for unobserved worker ability, the coefficient on the Raven type test score should be positive and statistically significant. Column (1) reports the test score coefficient: in column (2), the test score is replaced with a dummy that takes the value 1 if individual i was among the top 10\% test performers. Columns (3) and (4) repeat (1) and (2) while including controls for individual, workplace and other relevant characteristics. As Table 5 shows, there are no signs of referral screening for worker ability: in fact, the R square in columns (1) and (2) is equal to zero. 
Both the sociality and the favoritism explanation - provided that favoritism brings in less able recruits - predict a negative and significant Raven type test coefficient in table 5 . The table 5 results are, accordingly, not consistent with these two rival explanations.

At the outset, the insignificance of the Raven coefficient could simply reflect that our ability test failed to capture the worker traits that matter in the labour markets of interest. However, the wage regression in Table 7 below highlights the relevance of our ability measure in these labour markets: a high Raven type test score is strongly and positively correlated with a worker's real wage. ${ }^{22}$

[INSERT TABLE 5 ABOUT HERE]

\subsection{Wage penalty and labor turnover}

\subsubsection{Referral wage penalty}

Our theory predicts that employers pay efficiency wages in jobs where the costs of worker opportunism exceed a threshold. Above the threshold, workers recruited through referral should face a wage penalty compared to those finding a similar job through the market/other channels. We use our entry wage data to examine this wage penalty prediction. Since first migrations occurred over an extensive time period, we first convert monthly nominal to real wages using the All India Consumer Price Index for industrial workers (CPI (IW)). ${ }^{23} 24$

Two routes to examining this prediction are, first, to use exacting data on the costs of worker opportunism by job type to attempt to estimate the threshold and make comparisons of referred and non-referred worker wages above and below this

\footnotetext{
${ }^{22}$ Note that insignificance in the referral regressions could still reflect limited power due to our small sample size. These findings should therefore be interpreted with caution.

${ }^{23}$ In these labour markets, wages are not always observed. Apprentices are often not paid a wage: similarly, a son starting in the family enterprise may not have a clearly defined wage. These observations could be included as zeroes $(\ln (0)+1)$, or dropped. For the results reported below, we drop observations with a zero wage.

${ }^{24}$ The Labour Bureau reports the index from 1968 onwards (see http://labourbureau.nic.in/CPI\%20IW\%20Prev\%20Indexes.htm). For the period 19551968, we use the Economic Survey (1968-69, table 5-2) which is available from http://indiabudget.nic.in/previouses.asp
} 
threshold. A pragmatic and inferential approach is to draw on historical parallels and evidence of worker discipline challenges in the context of interest and look for a threshold combining the above job classifications with data on wages.

While absenteeism and retention remain major employer concerns in India, the average annual labour turnover in manufacturing jobs in the United States as recently as the 1920s was 100 percent, with 200-400 percent turnover not unusual (James 1960). In developing country settings, we expect accentuated worker discipline challenges in informal jobs because of the limited scope for contract enforcement.

Table 6 reports average entry real wages (in natural log form) for job category 1 to 3, comparing referred and non-referred recruits. While real wages decline monotonically by job type for workers recruited through referral, a referral wage penalty is discernible only for workers in bottom-tier (category 3) jobs: this wage penalty is statistically significant at a $1 \%$ level.

Table 6 thus suggests that firms in our sample, on average, pay bottom tier workers recruited through referral less than similar workers recruited through other channels.

\section{[INSERT TABLE 6 ABOUT HERE]}

It is evident that this wage penalty could simply reflect observable and unobservable quality differences between referred and non-referred recruits. To sharpen our comparison, we thus and next filter out unobserved and other worker characteristics and other relevant covariates.

Conditional on being a migrant, what determines a job entrant's real wage in the urban destinations and labor markets where meaningful wage comparisons between referred and non-referred workers can be made? Table 7, column 1, reports a simple, orthodox Mincerian wage equation with the real entry wage as dependent variable: on the right hand side we include standard, observable individual characteristics: education is represented by three dummy variables for the level of schooling completed: ${ }^{25}$ age at migration proxies work experience. The dummy for the top $10 \%$ Raven score controls for unobserved, individual ability.

\footnotetext{
${ }^{25}$ The results do not change if years of schooling replaces the educational dummies.
} 
We also include dummy variables for the main sector of work and for belonging to the largest social group. Finally, we include destination dummies to control for distance and other destination unobservables.

To assess the wage penalty prediction, we include a referral dummy, the referral dummy interacted with a category 3 job and a category 3 job control. While the referral and category 3 job dummy coefficients are statistically insignificant, the category 3 interaction term is consistent with table 6 and a wage penalty in bottom tier jobs for workers recruited through referral.

While supportive of our theory, a referral wage penalty is not consistent with Simon and Warner's (1992) matching explanation, which predicts an initial wage premium. It is also not consistent with the favoritism/nepotism mechanism which predicts lower wages if referred workers have inferior individual traits: we reiterate that our Raven type test does not support this 'favoritism as costly for the firm' conjecture. ${ }^{26}$

Given our inferential approach, the finding that the wage penalty prediction is supported for bottom tier jobs is original and interesting but needs to be interpreted with caution and as suggestive.

\subsubsection{Labor turnover}

To substantiate the relevance of retention challenges in bottom tier jobs, Table A3 (Online Appendix) presents a t-test of the share of short term labour turnover for referred and non-referred workers in category 3 jobs.

Short term retention challenges are nontrivial: $30 \%$ of the non-referred workers had left within six months of joining their first migrant job. For workers recruited through referral, $13 \%$ had left within six months. In addition, workers recruited through referral had $64 \%$ (or 14 months) longer workspells in their first migrant

\footnotetext{
${ }^{26}$ For the other rival explanations in Table 4, the information mechanism makes no wage predictions, while Montgomery's (1991) screening mechanism predicts a referral wage premium since referred workers (on average) should be more able and productive. The predictions of the sociality mechanism plausibly overlap with our model. Notice that Kugler (2003:532) predicts a wage premium since workplace referrals "generate segmentation in the labor market: referrals match 'good' high-paying jobs to well-connected workers, while formal methods match less attractive jobs to less-connected workers".
} 
jobs than those hired through other channels. Both differences are significant at a 5\% level. Adding controls, columns 2 and 3 in Table 7 report regressions with short term retention and workspell duration (in months) as dependent variables: it is evident that recruitment through referral correlates with significantly lower turnover and significantly longer workspells. Notice that there is no sign of referral acting as a disciplining device in other types of jobs: as a device for controlling turnover, employer advantages of referral appears to be strictly confined to bottom tier, category 3 jobs.

\section{[INSERT TABLE 7 ABOUT HERE]}

Keeping bottom-tier workers sufficiently content not to leave, given the strenuous manual labour and other menial, low-status tasks in often unattractive work environments, presents the informal enterprises in our sample with serious challenges and offer a plausible rationale for the strong tie and high stake referee referral patterns that we observe. While the high turnovers resonate with history and with Blattman and Dercon (2018), the turnover curbing effects of referral are also consistent with Simon and Warner (1992).

These turnover results are not, however, fully consistent with the notion of an efficiency wage equilibrium in our model. In equilibrium, and conditional on efficiency wage payments, the turnover of referred and other workers should be the same, but lower than turnover among workers who are paid reservation wages. That referred workers stay longer than non-referred workers in bottom-tier jobs is suggestive of a mixture of efficiency and reservation wage payments to nonreferred workers. If this is correct, the positive referral effect on turnovers and workspells in bottom tier jobs should be driven by a higher turnover among the subset of non-referred workers who are not paid efficiency wages. ${ }^{27}$

Our wage data facilitate a check of this conjecture. As reported in Table A4 (Online Appendix), while the average wages of non-referred workers in bottom tier

\footnotetext{
${ }^{27}$ To be explicit, let $x$ be the fraction of workers in bottom tier jobs who are paid reservation wages, $w$ and $1-x$ the fraction paid efficiency wages, $w_{S . .} w$ denotes referral wage. Let $t_{R}$ denote turnover among referred workers in these jobs and $t_{S}$, turnover among non referred workers who are paid efficiency wages while $t_{0}$ represents the turnover among non referred workers who get paid $w$ in these jobs. Then we have, in our data, $w_{R}<x . w+(1-x) w_{S}$ and $t_{R}<t_{0}(x)+t_{S}(1-x)$. In equilibrium, our model predicts that $t_{R}=t_{S}$. Thus the second inequality can be simplified to $\left(t_{R}-t_{0}\right) x<0$. Hence, as long as $x>0$, it is possible for both inequalities to hold.
} 
jobs are higher (because of the referral wage penalty), the turnover in the bottom half of the wage distribution is significantly lower among workers recruited through referral than among workers recruited through other channels. In contrast, the turnover difference in the upper half of the wage distribution is not significantly different from 0 . This provides suggestive support for the idea that the referral/non-referral turnover difference is driven by higher turnover among non-referred workers in the bottom half of the wage distribution who, we assume, are paid reservation wages.

\section{Conclusion}

We present a new theoretical model where firms use employee referral to curb moral hazard in the workplace. Employers can exploit the social tie between a workplace referee and a new recruit to leverage desirable recruit behaviour at a lower cost. This mechanism will only work when existing staff with high stakes in recruit performance can be mobilized as referees: our model predicts a strong tie between a referee and a recruit in this case.

A high prevalence of such referrals in a labour market requires that strong tie networks can be leveraged to supply suitable job candidates. This capacity on the part of strong tie networks is particularly plausible for low and unskilled jobs which are jobs that anyone in principle can do. The prevalence of low and unskilled occupations, informality (e.g. Kotwal et al 2011), limited scope for contract enforcement, informational constraints and hard working conditions (e.g. Blattman and Dercon 2018) make our theory especially relevant for developing country settings.

Results from the empirical literature and our descriptive statistics support the main and somewhat counterintuitive predictions of our model: we observe a high incidence of referral which is consistent with WB (2006) (Table A1) and Munshi and Rosenzweig's (2006) findings for blue collar workers in Mumbai. We also find entry through a strong social tie to be common. While referees, as predicted, are in more prestigious, high stake jobs, recruitment typically occurs into manual, bottom tier jobs (Figure 2). 
To shed further light on the relevance of our theory, we first examined whether alternative theories and explanations for referral could also account for these notable patterns in our data (Table 4, panel A): the information and the Montgomery (1991) selection (screening) explanations are hard to reconcile with our observations. For the sociality explanation, we would expect the referee and the recruit to be in the same type of jobs which contrasts with what we observe.

Using Raven-type test data, our findings are consistent with our moral hazard explanation, but provide little support for referral screening for unobserved worker ability or for the other rival explanations. For the nepotism explanation, the conjecture that 'favoritism is costly for the firm' - through lower recruit ability is not supported.

For the more specific predictions of our model, which are consistent with but offer more nuance than Antoninis (2006) and Heath (2018), ${ }^{28}$ we find a wage penalty for workers recruited through referral but only into bottom tier jobs: these informal, low status jobs involve hard manul labor and likely acute retention and discipline problems. Montgomery (1991), Kugler (2003) and Simon and Warner (1992) all predict a referral wage premium, which is inconsistent with our observations: there would be no referral wage penalty after controlling for worker ability if the 'favoritism as costly for the firm' explanation was correct.

Our labor turnover findings are in line with historical and ethnographic evidence, with official data and with e.g. recent observations of retention challenges in manufacturing jobs in Ethiopia. As discussed (and formalised in footnote 27), the finding of a turnover-reducing referral effect in bottom tier jobs is consistent with a situation where the comparator group of non-referred workers are paid a mixture of efficiency and reservation wages. Finally, our simple wage regression verified the relevance of our unobserved ability measure in the jobs and labour markets of interest: we find a large positive correlation between a top Raven-type test score and wages in these labour markets.

We reiterate that our findings are based on data from a small sample and from two villages and should therefore be treated with caution, as suggestive and, we hope, as a starting point for new research. While the main rival explanations

\footnotetext{
${ }^{28}$ Since we find a wage penalty after controlling for recruit ability.
} 
may contribute to the high job entry through workplace insiders, they are hard to reconcile with the observations and analyses presented here. Our results support Kugler's (2003) and Heath's (2018) work which see moral hazard as an important driver of workplace referrals, but add fine-grained empirical observations and new theoretical insights about how social ties and referee incentives shape referral prevalence and outcomes. 


\section{References}

Antoninis, Manos. 2006. "The wage effects from the use of personal contacts as hiring channels." Journal of Economic Behavior \& Organization 59(1): 133-146.

Banerji, Sanjay., Rajesh Natarajan and Kunal Sen. 2011. "Monitoring Costs, Credit Constraints and Entrepreneurship", mimeo, IDPM, University of Manchester.

Beaman, Lori and Jeremy Magruder. 2012. "Who gets the job referral? Evidence from a social networks experiment." American Economic Review 102(7): 3574-93.

Blattman, Christopher and Stefan Dercon. 2018. "The Impacts of Industrial and Entrepreneurial Work on Income and Health: Experimental Evidence from Ethiopia." American Economic Journal: Applied Economics 10(3): 1-38

Boissiere, M., John B. Knight and Richard H. Sabot. 1985. "Earnings, Schooling, Ability and Cognitive Skills." American Economic Review 75(5): 1016-1030.

Bramoullé, Yann and Sanjeev Goyal. 2016. "Favoritism." Journal of Development Economics 122 (2016): 16-27.

Calvo-Armegnol, Antoni and Matthew O. Jackson. 2004. "The Impacts of Social Networks on Employment and Inequality." American Economic Review 94(3): 426-54.

De Neve, Geert.2008. "We are all Sondukarar (Relatives)! Kinship and its morality in an urban industry of Tamilnadu, India,." Modern Asian Studies 42(1): 21146.

Dreze, Jean and Haris Gazdar. 1998. "Uttar Pradesh: The burden of inertia." in Indian Development - Selected Regional Perspectives, ed Jean Dreze and Amartya Sen. New Delhi: Oxford University Press.

Fafchamps, Marcel and Alexander Moradi. 2015. "Referral and job performance: 
evidence from the Ghana Colonial Army." Economic Development and Cultural Change 63(4): 715-51.

Granovetter, Mark. 1973. "The strength of weak ties." American Journal of Sociology 78: 1360-80.

Granovetter, Mark. 1995. Getting a Job: A Study of Contracts and Careers. 2nd edition. Chicago: Chicago University Press.

Heath, Rachel. 2018. 'Why do firms hire using referrals? Evidence from Bangladeshi Garment Factories.' Journal of Political Economy 126(4):1691-1746.

Holmstrom, Mark. 1984. Industry and Inequality: The social anthropology of Indian labour. Cambridge: Cambridge University Press.

Iversen, Vegard, Kunal Sen, Arjan Verschoor and Amaresh Dubey. 2009. "Job recruitment networks and migration to cities in India." Journal of Development Studies 45(4): 522-43.

James, Ralph. C. 1960. "The Casual Labor Problem in Indian Manufacturing." Quarterly Journal of Economics 74(1): 100-116.

Kajisa, Kei. 2009. "Personal Networks and Nonagricultural employment: The Case of a Farming Village in the Philippines." Economic Development and Cultural Change 55(4): 669-707.

Karlan, Dean., Markus Mobius, Tanya Rosenblat and Adam Szeidl. 2009. "Trust and Social Collateral." Quarterly Journal of Economics 124(3): 1307-1361.

Kerr, Clark., John T. Dunlop, Frederick H. Harbison and Charles A. Myers. 1966. Industrialism and Industrial Man. The Problem of Labor Management in Economic Growth. Cambridge, MA: Harvard University Press.

Kono, Hisaki. 2006. "Employment with connections: negative network effects." Journal of Development Economics 81: 244-258. 
Kotwal, Ashok, Bharat Ramaswami and Wilima Wadhwa. 2011. "Economic Liberalization and Indian Economic Growth: What's the Evidence?" Journal of Economic Literature 49(4): 1152-99.

Kugler, Adriana. 2003. "Employee referrals and efficiency wages." Labour Economics 10: 531-56.

Lucas, Robert E. B. 1993. "Internal Migration in Developing Countries." in Handbook of Population and Family Economics, ed. Mark R. Rosenzweig and Oded Stark. Amsterdam: Elsevier Science Publishers.

Mani, Anandi, Sendhil Mullainathan, Eldar Shafir and Jiaying Zhao (2013): "Poverty Impedes Cognitive Function." Science 341 (6149): 976-80.

Montgomery, James D. 1991. "Social networks and labour market outcomes: toward an economic analysis." American Economic Review 81(5): 1408-18.

Mortensen, Dale T. and Tara Vishwanath. 1994. "Personal contacts and earnings: It is who you know." Labour Economics 1: 187-201.

Munshi, Kaivan. 2003. "Networks in the Modern Economy: Mexican migrants in the US labour market." Quarterly Journal of Economics 118(2): 549-99.

Munshi, Kaivan and Mark R. Rosenzweig. 2006. "Traditional institutions meet the modern world: Caste, Gender and Schooling Choice in a Globalizing Economy." American Economic Review 96(4): 1225-52.

Pistaferri, Luigi. 1999. "Informal networks in the Italian labor market." Giornale degli Economisti e Annali di Economia 58: 355-375.

Pollard, Sidney. 1963. "Factory Discipline in the Industrial Revolution." The Economic History Review 16(2): 254-71.

Salop, Stephen C. 1979. "A model of the natural rate of unemployment." American Economic Review 69 (1): 117-125. 
Shapiro, Carl and Joseph E. Stiglitz. 1984. "Equilibrium unemployment as a worker discipline device." American Economic Review 74(3): 433-444.

Simon, Curtis J. and John T. Warner. 1992. "Matchmaker, matchmaker: the effect of old boys networks on job-match quality, earnings and tenure." Journal of Labor Economics 10(3): 306-30.

Smith, James P. and Duncan Thomas. 2003. "Remembrance of Things Past: Test- Retest Reliability of Retrospective Migration Histories." Journal of Royal Statistical Society 166(1): 23-49.

Topa, Giorgio. 2011. "Labour Markets and Referrals." in Handbook of Social Economics, ed. Jess Benhabib, Alberto Bisin and Matthew O. Jackson. Amsterdam: Elsevier Science Publishers.

van der Veen, Klaas. 1979. "Urbanization, migration and primordial attachments." in Winners and losers: styles of development in an Indian region, ed. S. D. Pillai and C. Baks. Bombay: Popular Prakashan.

Wahba, Jacline and Zenou, Yves. 2005. "Density, social networks and job search methods: Theory and application to Egypt." Journal of Development Economics 78(2): $443-473$.

Winters, Paul, Alain de Janvry and Elisabeth Sadoulet (2001): 'Family and community networks in Mexico-US migration', Journal of Human Resources 36(1): $159-84$. 
Table 1. Migration pattern by social group

$\begin{array}{llll} & \text { Ansaris } & \text { Chamars } & \text { Others } \\ \text { Share of migrant sample } & 48.4 \%(139) & 34.1 \%(98) & 17.4 \%(50) \\ \text { Mean age at time of first } & 16.0 & 19.3 & 19.5 \\ \text { migration } & (4.39) & (6.01) & (6.85) \\ \text { Mean yrs of schooling at } & 3.4 & 5.8 & 7.4 \\ \text { time of first migration } & (4.04) & (3.64) & (4.75) \\ \text { Dominant first employment } & \begin{array}{l}\text { Bakery } \\ \text { sector }\end{array} & \begin{array}{l}\text { Construction \& } \\ \text { agriculture }\end{array} & \begin{array}{l}\text { "Skilled" } \\ \text { private sector } \\ (83.4 \%)\end{array} \\ & & (31.6 \%) & (40.0 \%)\end{array}$




\section{Table 2. Mode of job entry}

Pre-arranged

Workplace referral

Indirect

Other

Not pre-arranged

Workplace referral

Indirect

Other
$\mathbf{N}$

Share

$88.9 \%$

167

$58.2 \%$

$18.1 \%$

$12.6 \%$

$11.1 \%$

$3.1 \%$

$1.7 \%$

$6.3 \%$ 
Table 3. Social ties and workplace referral

Relation to referee

Member of the same household

Other relative

Village friend

Village acquaintance

Friend from elsewhere

Acquaintance from elsewhere

Other
N Percentage Cumulative

$\begin{array}{lll}51 & 29.0 \% & 29.0 \% \\ 87 & 49.4 \% & 78.4 \% \\ 7 & 4.0 \% & 82.4 \% \\ 21 & 11.9 \% & 94.3 \% \\ 2 & 1.1 \% & 95.4 \% \\ 6 & 3.5 \% & 98.9 \% \\ 2 & 1.1 \% & 100 \%\end{array}$




\section{Table 4. Workplace referral - theories and predictions}

\begin{tabular}{|c|c|c|c|c|c|c|}
\hline $\begin{array}{l}\text { Referral } \\
\text { theory or } \\
\text { explanation/ } \\
\text { Empirical } \\
\text { prediction }\end{array}$ & MH & (i)Information & $\begin{array}{l}\text { (ii) Selection } \\
\text { or screening } \\
\text { (Montgomery } \\
\text { 1991) } \\
(3) \\
\end{array}$ & (iii) Sociality & (iv) Matching & $\begin{array}{l}\text { (v) Nepotism } \\
\text { (6) }\end{array}$ \\
\hline $\begin{array}{l}\text { PANEL A } \\
\text { Referee is in } \\
\text { workplace }\end{array}$ & Yes & $\begin{array}{l}\text { Yes (for our } \\
\text { comparison) }\end{array}$ & Yes & Yes & Yes & $\begin{array}{l}\text { Yes (for our } \\
\text { comparison) }\end{array}$ \\
\hline $\begin{array}{l}\text { Strength of } \\
\text { tie between } \\
\text { referee and } \\
\text { recruit }\end{array}$ & Strong & Weak & Weak & Strong & No prediction & Strong \\
\hline $\begin{array}{l}\text { Referee stake } \\
\text { in recruit } \\
\text { performance } \\
\text { (referee job } \\
\text { relative to } \\
\text { recruit job) }\end{array}$ & $\begin{array}{l}\text { High } \\
\text { (Higher } \\
\text { level) }\end{array}$ & $\begin{array}{l}\text { Low } \\
\text { (Same level) }\end{array}$ & $\begin{array}{l}\text { High } \\
\text { (Same level) }\end{array}$ & $\begin{array}{l}\text { Low } \\
\text { (Same level) }\end{array}$ & $\begin{array}{l}\text { No prediction } \\
\text { (Same level) }\end{array}$ & $\begin{array}{l}\text { Low } \\
\text { (No } \\
\text { prediction) }\end{array}$ \\
\hline $\begin{array}{l}\text { PANEL B } \\
\text { Unobserved } \\
\text { ability of } \\
\text { recruit } \\
\text { relative to } \\
\text { non-referred } \\
\text { worker }\end{array}$ & $\begin{array}{l}\text { No } \\
\text { difference }\end{array}$ & No prediction & Higher & Lower & No prediction & $\begin{array}{l}\text { Lower (for our } \\
\text { comparison) }\end{array}$ \\
\hline $\begin{array}{l}\text { Wage: } \\
\text { referred } \\
\text { recruit } \\
\text { relative to } \\
\text { non-referred } \\
\text { recruit for } \\
\text { similar job }\end{array}$ & $\begin{array}{l}\text { Wage } \\
\text { penalty for } \\
\text { job with high } \\
\text { cost of } \\
\text { oppor- } \\
\text { tunism: } \\
\text { Wage } \\
\text { premium } \\
\text { otherwise }\end{array}$ & No difference & $\begin{array}{l}\text { Wage } \\
\text { premium }\end{array}$ & Wage penalty & $\begin{array}{l}\text { Wage } \\
\text { premium }\end{array}$ & $\begin{array}{l}\text { Wage penalty } \\
\text { if lower ability } \\
\text { recruit }\end{array}$ \\
\hline $\begin{array}{l}\text { Labour } \\
\text { turnover: } \\
\text { referred } \\
\text { recruit } \\
\text { relative to } \\
\text { non-referred } \\
\text { recruit for } \\
\text { similar job }\end{array}$ & $\begin{array}{l}\text { No } \\
\text { difference }\end{array}$ & No difference & No difference & Lower & Lower & No prediction \\
\hline
\end{tabular}


Table 5. Raven type test score and referrals

$\begin{array}{lcccc} & \text { Workpl ref } & \text { Workpl ref } & \text { Workpl ref } & \text { Workpl ref } \\ \text { Raven type test score } & 0.020 & & 0.019 & \\ & (0.026) & & (0.028) & \\ \text { Raven top 10\% } & & 0.011 & & 0.009 \\ & & (0.097) & & (0.11) \\ \text { Individual controls } & \text { no } & \text { no } & \text { yes } & \text { yes } \\ \text { Workplace controls } & \text { no } & \text { no } & \text { yes } & \text { yes } \\ \text { Destination dummies } & \text { no } & \text { no } & \text { yes } & \text { yes } \\ \text { R squared } & 0.002 & 0.000 & 0.25 & 0.25 \\ \text { Observations } & 268 & 268 & 266 & 266\end{array}$

Note: OLS with robust SEs (in parentheses). ${ }^{* * *},{ }^{* *},{ }^{*}$ significant at 1,5 and $10 \%$ level. Individual controls: age at migration; dummies for primary (class 1-5), secondary (class 6-10) and higher education (Above class 10). Other controls: bakery sector dummy, destination dummies. 
Table 6. Mean real entry wage: referred vs non-referred workers

$\begin{array}{ccccc}\text { Job type } & \mathbf{N} & \text { Referred workers } & \text { Non-referred workers } & \text { Difference } \\ \text { Category 1 } & 55 & 6.35(32) & 6.35(23) & 0.00 \\ \text { Category 2 } & 80 & 5.47(52) & 5.56(28) & -0.09 \\ \text { Category 3 } & 127 & 5.09(70) & 5.75(57) & -0.66^{* * *}\end{array}$




\section{Table 7. Determinants of real wage, job turnover and workspell}

\begin{tabular}{|c|c|c|c|}
\hline & Real entry wage & $\begin{array}{l}\text { Short term turnover } \\
\text { (Dummy valued } 1 \text { if } \\
\text { workspell less } \\
\text { than } 6 \text { months) }\end{array}$ & $\begin{array}{c}\text { Duration of first } \\
\text { workspell (months) }\end{array}$ \\
\hline \multirow[t]{2}{*}{ Referral } & 0.084 & $0.14^{*}$ & -5.70 \\
\hline & $(0.16)$ & $(0.07)$ & $(10.04)$ \\
\hline \multirow[t]{2}{*}{ Referral X category 3 job dummy } & $-0.43^{* *}$ & $-0.30 * * *$ & $23.3^{*}$ \\
\hline & $(0.21)$ & $(0.11)$ & $(11.85)$ \\
\hline \multirow[t]{2}{*}{ Category 3 job dummy } & -0.0466 & 0.112 & $-29.04^{* * *}$ \\
\hline & $(0.167)$ & $(0.093)$ & $(9.46)$ \\
\hline \multirow[t]{2}{*}{ Age at migration } & $0.037^{* * *}$ & $-0.014^{* * *}$ & $2.52^{* * *}$ \\
\hline & $(0.01)$ & $(0.004)$ & $(0.90)$ \\
\hline \multirow[t]{2}{*}{ Raven top $10 \%$} & $0.50^{* * *}$ & -0.028 & $-18.56^{* *}$ \\
\hline & $(0.15)$ & $(0.08)$ & $(9.29)$ \\
\hline \multirow[t]{2}{*}{ Primary } & 0.084 & -0.002 & -6.46 \\
\hline & $(0.16)$ & $(0.07)$ & $(8.55)$ \\
\hline \multirow[t]{2}{*}{ Secondary } & 0.057 & $0.087^{*}$ & $-19.42^{* *}$ \\
\hline & $(0.12)$ & $(0.071)$ & $(7.75)$ \\
\hline \multirow[t]{2}{*}{ Higher } & 0.062 & 0.08 & $-29.15^{* *}$ \\
\hline & $(0.227)$ & $(0.14)$ & $(11.96)$ \\
\hline \multirow[t]{2}{*}{ Ansari } & $-0.27^{* *}$ & $-0.30^{* * *}$ & 10.15 \\
\hline & $(0.135)$ & $(0.08)$ & $(9.14)$ \\
\hline \multirow[t]{2}{*}{ Bakery } & -0.104 & 0.13 & -3.82 \\
\hline & 0.147 & 0.08 & 7.73 \\
\hline Destination dummies & YES & YES & YES \\
\hline$R^{2}$ & 0.31 & 0.19 & 0.24 \\
\hline $\mathrm{N}$ & 259 & 258 & 258 \\
\hline
\end{tabular}

